\title{
Visual and different automatic scoring profiles of respiratory variables in the diagnosis of sleep apnoea-hypopnoea syndrome
}

\author{
O. Carrasco*, J.M. Montserrat*, P. Lloberes*, C. Ascasco**, \\ E. Ballester*, C. Fornas*, R. Rodriguez-Roisin*
}

Visual and different automatic scoring profiles of respiratory variables in the diagnosis of sleep apnoea-hypopnoea syndrome. O. Carrasco, J.M. Montserrat, P. Lloberes, C. Ascasco, E. Ballester, C. Fornas, R. Rodriguez-Roisin. (CERS Journals Ltd 1996.

ABSTRACT: The purpose of our study was to explore the diagnostic accuracy of different methods of scoring night time recording of respiratory variables (NTRRV) for the diagnosis of the sleep apnoea-hypopnoea syndrome (SAHS).

Within a 2 week period, we performed a partially attended night time recording of respiratory variables and a full polysomnography (PSG) for reference in patients with suspected SAHS. Night time recording of respiratory variables was carried out using equipment which records, and continuously displays on a monitor, oximetry, airflow, chest and abdominal motion and body position. Night time recording of respiratory variables was scored manually and automatically, according to different combinations of the parameters described previously. Full polysomnography was performed in the Sleep Laboratory following conventional standards.

Thirty six patients were studied. Visual analysis and different automatic scoring profiles of night time recording of respiratory variables were compared to full polysomnography in terms of agreement, sensitivity and specificity. Visual scoring of night time recording of respiratory variables gave the finest agreement-sensitivity-specificity relationship. Automatic scoring of nighttime recording of respiratory variables showed a trend to underestimate the apnoea-hypopnoea index (AHI) with respect to full polysomnography due mainly to underrecognition of hypopnoeas. Agreement-sensitivity-specificity relationships of automatic night time recording of respiratory variables with respect to full polysomnography varied depending on the automatic profile used. Some had a good agreement and sensitivity whilst others had a good specificity.

These findings show that visual scoring of night time recording of respiratory variables is the most accurate method of analysis when compared to full polysomnography. The usefulness of the automatic methods of scoring of respiratory variables depends on the end-point chosen and is not reliable enough to be used in all situations. Night time recording of respiratory variables represents a real complement to conventional full polysomnography in clinical practice.

Eur Respir J., 1996, 9, 125-130.

\begin{abstract}
* Servei de Pneumologia i Al.lèrgia Respiratòria, **Unitat d'Epidemiologia $\mathrm{i}$ Bioestadistica, Hospital Clínic, Departament de Medicina, Universitat de Barcelona, Barcelona, Spain.
\end{abstract}

Correspondence: J.M. Montserrat Servei de Pneumologia i Al.lèrgia Respiratòria Hospital Clinic

Villarroel 170

08036 Barcelona

Spain

Received: September 131994

Accepted after revision September 91995

Supported by a grant (92/0771) from FIS and by Comissionat per Universitats i Reserca de la Generalitat de Catalunya (GRQ 94-9103).
Sleep apnoea-hypopnoea syndrome (SAHS) is a disorder with a high prevalence, ranging 1-4\% [1]. Morbidity and mortality are exceedingly high in this condition and effective treatment exists for symptomatic patients [2]. Although the diagnostic gold standard procedure for SAHS is full polysomnography (PSG), alternative tools are needed to avoid having to refer all patients for further costly, labour-intensive and time-consuming full PSG.

Recently, it has been stated that recorded electrophysiological parameters are of debatable value in SAHS as this condition can be accurately defined by the apnoeahypopnoea index (AHI) obtained either by the time spent in bed or by time asleep [3]. As a consequence, night time recording of respiratory variables (NTRRV) has emerged as one of the most widely used alternatives. Although equipment is constantly being developed to allow a simplified diagnosis of SAHS only a few systems are well validated [4]. However, the accuracy of the NTRRV probably depends not only on which variables are recorded or whether attendance is complete or partial, but, most of all, on the scoring procedure. More precisely, like the automatic scoring of respiratory variables from full PSG, automatic scoring from NTRRV needs further study to be on a par with visual scoring.

The purpose of our study was thus to explore the value and accuracy of visual scoring and different automatic profiles of scoring NTRRV in patients with suspected SAHS. 


\section{Methods}

\section{Patients}

The study population consisted of 36 consecutive patients referred to the Sleep Clinic of our Service for evaluation of SAHS. Within a 2 week period, diagnostic sleep studies were performed at random in two settings: 1) in the Sleep Laboratory using full PSG; and 2) in the respiratory ward using NTRRV only. This study was approved by the Ethics Committee of our hospital.

\section{Overnight Full PSG}

This included electroencephalogram (EEG) (C4/A1, C3/A2, O2/A1, O1/A2), chin electromyogram and electrooculogram recordings for sleep staging according to standard criteria [5]. Arterial oxygen saturation $\left(\mathrm{Sa}_{\mathrm{a}} \mathrm{O}_{2}\right)$ was measured continuously with a finger probe using a pulse oximeter (504 Critical Care System Inc., Waukesha, WI, USA). Rib cage and abdominal motion were monitored using piezoelectric bands placed over the thorax and abdomen (Resp-Ez, Tm Bionic, Midlothian, VA, USA). Oronasal flow was assessed using a thermistor. All signals were recorded continuously on a polygraph (Nicolet 1A98, Madison, WI, USA). Respiratory events were defined according to commonly used clinical criteria of cessation of airflow lasting $10 \mathrm{~s}$ or more for apnoeas and a $10 \mathrm{~s}$ or more period of any discernible airflow reduction associated with an arousal or with a cyclical dip of $\mathrm{Sa}_{\mathrm{a}} \mathrm{O}_{2}$ for hypopnoeas. Arousal was scored following the American Sleep Disorders Association; briefly, abrupt shift of $3 \mathrm{~s}$ at least in EEG frequency, which may include theta, alpha, or frequencies greater than $16 \mathrm{~Hz}$, subject to various conditions [6].

\section{Night time recording of respiratory variables (NTRRV)}

This was performed using a Densa Pneumograph (Densa Ltd, Flint, UK), which measures oronasal flow by means of a thermistor, and chest and abdominal motion using strain gauges throughout the night. The same pulse oximeter as for full PSG was used. A body position sensor generates a signal differentiating between left and right sides and supine position. The analogue signals were digitalized and displayed on the computer screen, and stored on the computer hard disk. We started to record the NTRRV some minutes after the lights were off when we feel that the patient is sleeping (around 5-15 min). The study finished when we realized, visually, that the patient was awake. The morning after the study, a trained physician (JMM) scored the NTRRV reviewing the tracings in 2 min screens. Using a manual counter, like those used in the haematology laboratory, the number of apnoeas and hypopnoeas were scored over approximately $15 \mathrm{~min}$. Respiratory events were defined according to the following definitions: a cessation of airflow lasting $10 \mathrm{~s}$ or more for apnoeas and a $10 \mathrm{~s}$ or more period of any discernible airflow reduction associated with a cyclical $\mathrm{Sa}, \mathrm{O}_{2}$ dip for hypopnoeas. An automatic scoring using different combinations of the parameters described above was then performed. Table 1 shows the characteristics of the different automatic profiles used. A judgement of the quality of the signal displayed on the screen was also performed using a scale, ranging from 0 (bad signal) to 3 (excellent signal).

\section{Statistical analysis}

The apnoea-hypopnoea indices measured with full PSG and with the different methods of scoring the NTRRV were expressed as mean \pm SEM. The usefulness between the measurements was assessed in two ways. Firstly, the accuracy of the measurements was assessed by the method suggested by BLAND and Altman [7]. The bias between any two measurements was estimated by the mean difference. The $95 \%$ confidence interval (95\% CI) of the bias was also calculated. Secondly, in order to

Table 1. - Characteristics and definitions of the different automatic profiles used

\begin{tabular}{|c|c|c|}
\hline \multicolumn{2}{|r|}{ Apnoea } & Hypopnoea \\
\hline \multicolumn{3}{|c|}{ a) Profiles where for apnoea definition a fall in $\mathrm{Sa}_{\mathrm{a}} \mathrm{O}_{2}$ is compulsory } \\
\hline 1. FA80(4)50(4) & $=80 \% \downarrow$ airflow with $4 \% \downarrow \mathrm{Sa}_{\mathrm{a}} \mathrm{O}_{2}$ & $50 \% \downarrow$ airflow and/or bands signals with $4 \% \downarrow \mathrm{Sa}_{\mathrm{a}, \mathrm{O}_{2}}$ \\
\hline 2. FA80(2)50(2) & $80 \% \downarrow$ airflow with $2 \% \downarrow \mathrm{Sa}_{\mathrm{a}} \mathrm{O}_{2}$ & $50 \% \downarrow$ airflow and/or bands signals with $2 \% \downarrow \mathrm{Sa}_{\mathrm{a}, \mathrm{O}_{2}}$ \\
\hline 3. FA80(4)35(4) & $80 \% \downarrow$ airflow with $4 \% \downarrow \mathrm{Sa}_{\mathrm{a}} \mathrm{O}_{2}$ & $35 \% \downarrow$ airflow and/or bands signals with $4 \% \downarrow \mathrm{Sa}_{\mathrm{a}, \mathrm{O}_{2}}$ \\
\hline 4. FA80(2)35(2) & $80 \% \downarrow$ airflow with $2 \% \downarrow \mathrm{Sa}_{\mathrm{a}} \mathrm{O}_{2}$ & $35 \% \downarrow$ airflow and/or bands signals with $2 \% \downarrow \mathrm{Sa}_{\mathrm{a}} \mathrm{O}_{2}$ \\
\hline 5. $\mathrm{F} 80(4) 50(4)$ & $80 \% \downarrow$ airflow with $4 \% \downarrow \mathrm{Sa}_{\mathrm{a}, \mathrm{O}_{2}}$ & $50 \% \downarrow$ airflow signal with $4 \% \downarrow \mathrm{Sa}_{\mathrm{a}} \mathrm{O}_{2}$ \\
\hline 6. $\mathrm{F} 80(2) 50(2)$ & $80 \% \downarrow$ airflow with $2 \% \downarrow \mathrm{Sa}_{\mathrm{a}} \mathrm{O}_{2}$ & $50 \% \downarrow$ airflow signal with $4 \% \downarrow \mathrm{Sa}_{2} \mathrm{O}_{2}$ \\
\hline 7. $\mathrm{F} 80(4) 35(4)$ & $80 \% \downarrow$ airflow with $4 \% \downarrow \mathrm{Sa}_{\mathrm{a}} \mathrm{O}_{2}$ & $35 \% \downarrow$ airflow signal with $4 \% \downarrow \mathrm{Sa}_{\mathrm{a}, \mathrm{O}_{2}}$ \\
\hline 8. F80(2)50(2) & $80 \% \downarrow$ airflow with $2 \% \downarrow \mathrm{Sa}_{\mathrm{a}} \mathrm{O}_{2}$ & $35 \% \downarrow$ airflow signal with $2 \% \downarrow \mathrm{Sa}_{\mathrm{a}, \mathrm{O}_{2}}$ \\
\hline 9. A4\% & $80 \% \downarrow$ bands with $4 \% \downarrow \mathrm{Sa}_{\mathrm{a}} \mathrm{O}_{2}$ & $50 \% \downarrow$ bands signal with $4 \% \downarrow \mathrm{Sa}_{\mathrm{a}, \mathrm{O}_{2}}$ \\
\hline 10. A2\% & $80 \% \downarrow$ bands with $4 \% \downarrow \mathrm{Sa}_{\mathrm{a}, \mathrm{O}_{2}}$ & $50 \% \downarrow$ bands signal with $2 \% \downarrow \mathrm{Sa}_{\mathrm{a}, \mathrm{O}_{2}}$ \\
\hline 11. Angle $\mathrm{P}$ & Counts drops in phase angle of & $58^{\circ}$ in less than $15 \mathrm{~s}$ \\
\hline
\end{tabular}

b) Profiles where for apnoea definition a fall in $S \mathrm{a}, \mathrm{O}_{2}$ is not compulsory

The same profiles as above were analysed and were expressed putting a 0 inside the first parenthesis. For instance F80(0)50(4) means that for apnoea definition a fall in $\mathrm{Sa}_{\mathrm{a}, \mathrm{O}_{2}}$ is not compulsory but for hypopnoea definition (50\% reduction of flow) a $4 \%$ desaturation is needed.

$\downarrow$ : reduction; $\mathrm{Sa}_{\mathrm{a}} \mathrm{O}_{2}$ : arterial oxygen saturation. bands: thorax/abdominal piezoelectric bands, signalling movement. 
know the clinical importance of the agreement, visual and different automatic scoring profiles of the NTRRV (table 1) were compared to full PSG, at three cut-off points (AHI $>10$, AHI $>20$ and AHI $>30$ events $\cdot \mathrm{h}^{-1}$ ). These three AHI cut-off points were used to calculate the sensitivity, specificity and the coefficient of agreement (Kappa statistic) of the visual and the different automatic profiles of NTRRV with respect to full PSG. The results of the different automatic profiles of the NTRRV were also compared with the visual scoring of NTRRV at the three cut-off points.

\section{Results}

The mean age of the 36 patients ( 29 males) was $52 \pm 2$ yrs (range 27-62 yrs), and the mean body mass index was $32 \pm 1.1 \mathrm{~kg} \cdot \mathrm{m}^{-2}$ (range $23-45 \mathrm{~kg} \cdot \mathrm{m}^{-2}$ ). All patients were referred to our Sleep Laboratory to evaluate a SAHS. Figure 1 represents the mean number of apnoea and hypopnoea per hour (AHI) (Fig. 1a shows automatic profiles where for apnoea definition a fall in $\mathrm{Sa}, \mathrm{O}_{2}$ is compulsory; Fig. 1b shows automatic profiles where for apnoea definition a fall in $\mathrm{Sa}_{\mathrm{a}} \mathrm{O}_{2}$ is not compulsory). The column bars in the $\mathrm{X}$-axis represent the values of the respiratory events with the different profiles studied when apnoea and hypopnoea (white columns) or isolated number of apnoeas per hour (internal hatched columns) are considered. From left to right: the first two bars represent AHI values according to conventional full polysomnography (Full PSG) and the AHI obtained from Full PSG dividing the total number of respiratory events, instead by the sleep time, by the total time in bed (PSGb), respectively; the third bar represents the visual AHI scoring values obtained from the NTRRV. The remaining bars are the AHI values obtained from different NTRRV automatic profiles (see table 1 for detailed profile characteristics). It is evident from this figure that the main discrepancy in the AHI values from the different profiles analysed depends mainly on the hypopnoea component.

Table 2 shows the mean differences, standard deviation, standard error and the $95 \%$ CI comparing AHI obtained from full PSG with the visual and the different automatic methods of scoring NTRRV. The best results, i.e. smallest difference and the narrowest $95 \% \mathrm{CI}$, were those obtained by visual scoring of the NTRRV and the following automatic scoring profiles of NTRRV: FA80(2)35(2), FA80(0)50(2) and FA80(0)35(2). Very similar results were obtained when comparing visual
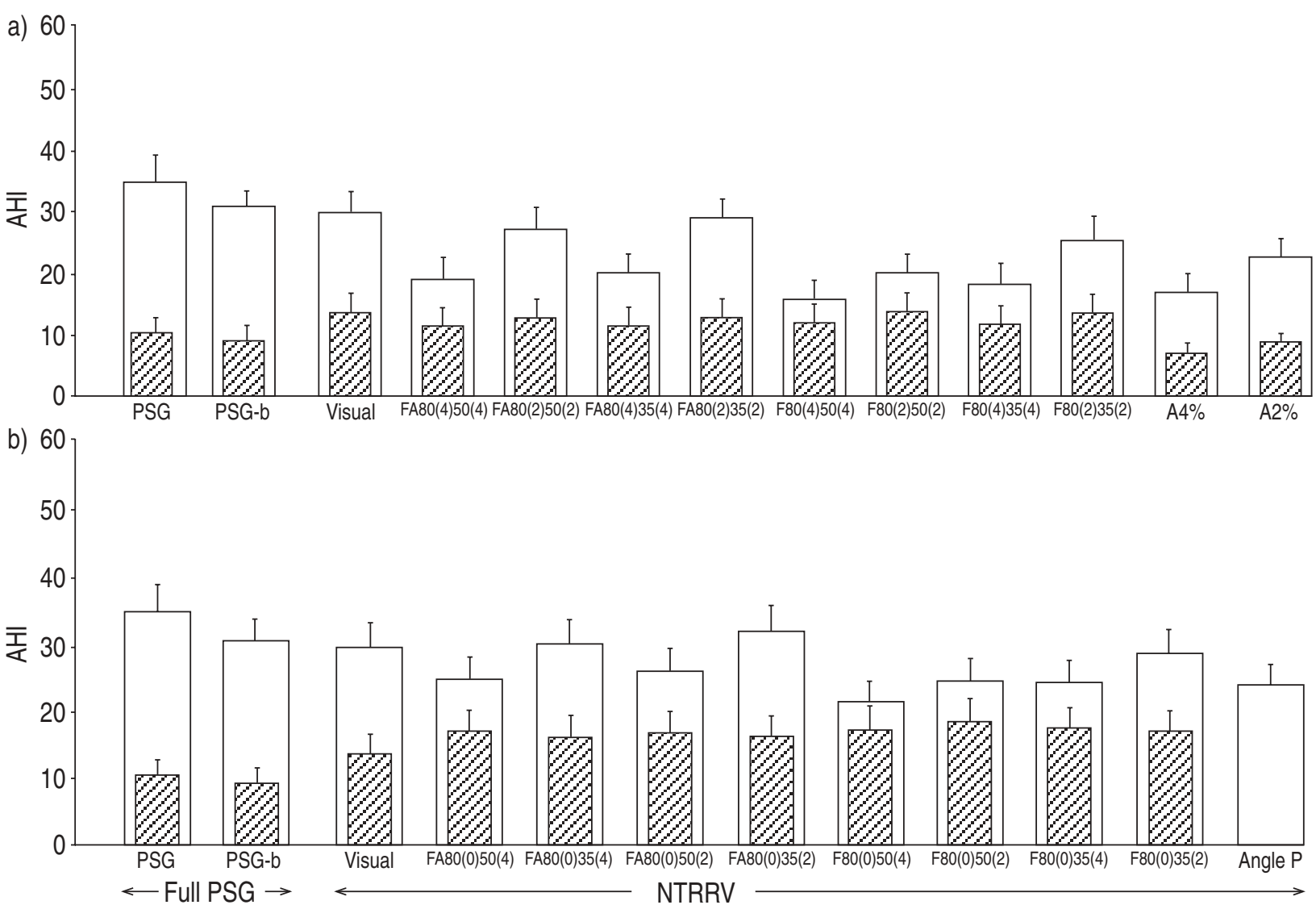

Fig. 1. - The bars on the X-axis represent the mean \pm SEM number of AHI (white columns) (hatched columns represent the isolated number of apnoeas) obtained from full PSG (first col: PSG); from full PSG dividing the total number of respiratory events, instead by the sleep time, by the total time in bed (second bar: PSG-b); the third bar (Visual) represents the manually scored AHI obtained from the NTRRV; and the remaining bars are the AHI values obtained from different NTRRV automatic profiles (see table 1 for detailed profile characteristics). a) Automatic profiles where for apnoea definition a fall in $\mathrm{Sa}_{2} \mathrm{O}_{2}$ is compulsory. b) Automatic profiles where for apnoea definition a fall in $\mathrm{Sa}, \mathrm{O}_{2}$ is not compulsory. AHI: apnoea-hypopnoea index; PSG: polysomnography; NTRRV: night time recording of respiratory variables; $S \mathrm{a}, \mathrm{O}_{2}$ : arterial oxygen saturation. 
Table 2. - Differences and 95\% confidence interval $(95 \% \mathrm{Cl})$ comparing $\mathrm{AHI}$ obtained from full PSG and the different methods of scoring NTRRV (visual and automatic)

\begin{tabular}{lcc}
\hline \multicolumn{1}{c}{ Profile $^{\dagger}$} & Difference & $95 \%$ CI \\
\hline Full PSG-Visual NTRRV & $5.2 \pm 13.1(2.21)$ & $9.54-0.85$ \\
Full PSG-FA80(4)50(4) & $15.7 \pm 15.4(2.6)$ & $20.8-10.64$ \\
Full PSG-FA80(2)50(2) & $7.94 \pm 14.2(2.4)$ & $12.6-3.2$ \\
Full PSG-FA80(4)35(4) & $14.7 \pm 15.3(2.6)$ & $19.8-9.7$ \\
Full PSG-FA80(2)35(2) & $6.0 \pm 14.7(2.5)$ & $10.0-1.1$ \\
Full PSG-F80(4)50(4) & $19.4 \pm 15.2(2.6)$ & $24.4-14.4$ \\
Full PSG-F80(2)50(2) & $14.7 \pm 13.8(2.3)$ & $19.3-10.2$ \\
Full PSG-F80(4)35(4) & $16.6 \pm 14.8(2.5)$ & $21.6-11.7$ \\
Full PSG-F80(2)35(2) & $9.5 \pm 13.8(2.3)$ & $14.1-5.0$ \\
Full PSG-A4\% & $18.0 \pm 16.5(2.8)$ & $23.4-12.4$ \\
Full PSG-A2\% & $11.8 \pm 17.0(2.9)$ & $17.4-6.2$ \\
Full PSG-FA80(0)50(4) & $10.1 \pm 14.3(2.4)$ & $14.8-5.3$ \\
Full PSG-FA80(0)50(2) & $4.8 \pm 14.0(2.4)$ & $9.4-0.2$ \\
Full PSG-FA80(0)35(4) & $9.0 \pm 14.4(2.4)$ & $13.8-4.2$ \\
Full PSG-FA80(0)35(2) & $2.9 \pm 14.6(2.5)$ & $7.7-2.0$ \\
Full PSG-F80(0)50(4) & $13.8 \pm 14.6(2.5)$ & $18.7-9.0$ \\
Full PSG-F80(0)50(2) & $10.6 \pm 14.0(2.4)$ & $15.2-6.0$ \\
Full PSG-F80(0)35(4) & $10.8 \pm 14.2(2.4)$ & $15.5-6.1$ \\
Full PSG-F80(0)35(2) & $6.4 \pm 13.9(2.3)$ & $11.1-1.8$ \\
Full PSG-Angle P & $11.0 \pm 16.8(2.8)$ & $16.6-5.5$ \\
\hline
\end{tabular}

Differences are presented as mean \pm SD, and SEM in parenthesis. PSG: polysomnography; NTRRV: night time recording of respiratory variables; AHI: apnoea-hypopnoea index; 95\% CI: 95\% confidence interval. $\pitchfork$ : see Table 1 and Fig. 1 for definition of profiles

and automatic scoring of the NTRRV, the above three automatic scoring profiles along with FA80(2)50(2) and F80(0)35(2) showing the best results (table $3 \mathrm{~b}$ ).

To assess the clinical relevance of the accuracy of the measurement according to the method of BLAND and Altman [7], sensitivity, specificity and agreement using Kappa statistic of full PSG AHI and the most precise methods of scoring NTRRV were calculated at a Full PSG AHI cut-off of 20 (table 3a). Note that visual scoring of NTRRV gave the best results. Table $3 \mathrm{~b}$ shows

Table 3. - Sensitivity and specificity comparing: a) full PSG AHI and the best methods of scoring NTRRV obtained on the basis of the method of BLAND and ALTMAN [7] at full PSG AHI cut-off of 20; b) visual scoring of NTRRV and the best methods of scoring NTRRV obtained on the basis of the method of BLAND and ALTMAN [7] at full PSG AHI cut-off of 20.

\begin{tabular}{lccc}
\hline & Sensitivity & Specificity & Kappa \\
\hline a) & & & \\
Visual NTRRV scoring & 94 & 82 & 0.77 \\
FA80(2)35(2) & 83 & 71 & 0.54 \\
FA80(0)50(2) & 89 & 76 & 0.65 \\
FA80(0)35(2) & 89 & 70 & 0.60 \\
b) & 90 & 86 & 0.77 \\
FA80(2)35(2) & 95 & 93 & 0.88 \\
FA80(0)50(2) & 95 & 87 & 0.82 \\
FA80(0)35(2) & & & \\
\hline
\end{tabular}

For abbreviations see legend to table 2 .
Table 4. - Judgement of the quality of the signals displayed on the screen, ranging from 0 (bad signal) to 3 (excellent signal). Values are \% of subjects with the different range of signals

\begin{tabular}{lcrcc}
\hline & \multicolumn{4}{c}{ Score } \\
& 0 & 1 & 2 & 3 \\
\hline $\mathrm{Sa}_{\mathrm{O}} \mathrm{O}_{2}$ & $0 \%$ & $3 \%$ & $11 \%$ & $86 \%$ \\
Flow & $0 \%$ & $3 \%$ & $12 \%$ & $85 \%$ \\
Abdomen & $0 \%$ & $6 \%$ & $25 \%$ & $69 \%$ \\
Thorax & $3 \%$ & $33 \%$ & $30 \%$ & $35 \%$ \\
\hline
\end{tabular}

$\mathrm{Sa}_{\mathrm{a}} \mathrm{O}_{2}$ : arterial oxygen saturation.

the same information comparing the visual scoring of NTRRV and the best NTRRV automatic scoring methods obtained on the basis of the method of BLAND and ALTMAN [7]. Nevertheless, analysing data from Appendix 1 and 2 , we would like emphasize that some profiles have a remarkable specificity (F80(4)50(4) and F80(2)50(2) $\mathrm{Sp}=100)$. F80(2)50(2) shows an excellent specificity with an acceptable sensitivity in any of the Full PSG AHI cut-off points studied, even if its agreement obtained by the method of BLAND and AltMAN [7] was not good (mean \pm SD difference $14 \pm 13$ with a $95 \%$ CI of 4.7 ), and thus could be used as a confirmatory diagnostic tool. Quality assessment of the signal displayed on the monitor screen during NTRRV is shown in table 4. It is remarkable that $\mathrm{Sa}_{\mathrm{a}} \mathrm{O}_{2}$ and flow signals displayed were scored as excellent in $86 \%$ of the cases; by contrast, thorax band signals had a lower consideration, with only $35 \%$ of the cases classified as excellent.

\section{Discussion}

This study suggests that visual scoring of NTRRV is the most accurate and useful method of analysis when compared to full PSG. It has two main advantages: 1) It has a good agreement with respect to full PSG and shows the best relationship between sensitivity and specificity compared to full PSG; and 2) using the computer screen, that automatically displays the entire study in a succession of 2 min screens, it can be read in only 15 min. We therefore, strongly suggest that this should be the main procedure to score NTRRV.

However, the automatic methods of scoring could be of help because they provide additional parameters, such as apnoea duration, minimum $\mathrm{Sa}_{\mathrm{a}} \mathrm{O}_{2}, \mathrm{CT} 90$ (\% of time spent at $\mathrm{Sa}_{\mathrm{a}} \mathrm{O}_{2}<90 \%$ ), snoring quantification and body position. In addition, use of the more specific methods should make it possible to confirm SAHS.

Night-to-night variability is probably one of the most important factors explaining the finding of a difference in the AHI obtained with the NTRRV compared with full PSG [8]. Although this factor seems to have a minor importance in patients with severe SAHS, variability at low AHI values can be fairly remarkable [8]. In addition, the AHI obtained with full PSG is calculated taking into account the efficient sleep time, whereas the NTRRV calculates the AHI from the total time of recording. Nevertheless, when AHI from the NTRRV was 
compared with AHI from full PSG but corrected by the total time spent in bed differences were minimized (fig. 1 , PSGb $v s$ visual). As the mean number of hypopnoeas but not the number of apnoeas obtained with the NTRRV was significantly lower than that corresponding to full PSG, this suggests that the main factor influencing the underestimation of the AHI using NTRRV automatic scoring is the underrecognition of hypopnoeas. Conceivably, this is due to the different criteria applied to the manual scoring in full PSG and the visual scoring of NTRRV with respect to the software program for automated codification of NTRRV monitoring.

Therefore, depending on the program analysis used in our study for NTRRV monitoring, apnoeas are recognized if there is a reduction of more than $80 \%$ of flow associated or not with a fall in $\mathrm{Sa}_{2} \mathrm{O}_{2}$ of $2-4 \%$. Hypopnoeas are recognized if there is a reduction of flow and/or thoracoabdominal movement in the order of $50-35 \%$, respectively, associated with at least a $2-4 \% \mathrm{Sa}_{\mathrm{a}} \mathrm{O}_{2}$ dip. Therefore, some of the profiles used may underestimate the apnoeas which are not associated to $\mathrm{Sa}, \mathrm{O}_{2}$ dips, or hypopnoeas with a reduction of airflow less than $35-50 \%$, or associated with arousals but not with $\mathrm{Sa}_{\mathrm{a}} \mathrm{O}_{2}$ dips. However, despite the fact that the agreement between the full PSG and the NTRRV is not perfect according to the method of Bland and Altman [7], we think that, as the criteria for treatment with continuous positive airway pressure (CPAP) is documented SAHS plus a clinical impairment more than the AHI itself, NTRRV could be useful, especially in moderate to severe SAHS. Although with the upper airway resistance syndrome cannot be detected with the present technology, the future incorporation of the flow contour characteristics could probably overcome such limitations [9]. Other authors have analysed different respiratory variables (phase angle changes, snoring plus oximetry) or have studied patients at home [10-15]. Some of these methods have shown good correlations between the respiratory disturbance index obtained with portable monitors and full PSG. However, these studies have been performed on both small and selected populations and have not addressed the issue of scoring methods.

In summary, in our setting, visual scoring of NTRRV is the most accurate and useful method of analysis for sleep monitoring purposes. Validated systems of NTRRV can be a very important support to clinical practice in the setting of the Sleep Clinic and their general implementation should probably markedly reduce the number of full PSG used nowadays for the diagnosis of SAHS. Furthermore, NTRRV may increase availability of sleep recordings, thereby increasing the total potential number of investigations that may be performed.

See appendices 1 and 2 on next page.

\section{References}

1. Young T, Palta M, Dempsey J, Skatrud J, Weber S, Badr $\mathrm{S}$. The occurrence of sleep-disordered breathing among middle-aged adults. N Engl J Med 1993; 328: 12301235.

2. He J, Kryger MH, Zorick FJ, Conway W, Roth T. Mortality and apnea index in obstructive sleep apnea: experience in 385 male patients. Chest 1988; 94: 9-14.

3. Douglas NJ, Thomas S, Jan MA. Clinical value of polysomnography. Lancet 1992; 339: 347-350.

4. American Sleep Disorders Association. Portable recording in the assessment of obstructive sleep apnea. APSS Newsletter, 1993.

5. Rechtschaffen A, Kales A, (eds). A manual of standardized terminology, techniques and scoring system for sleep stages of human subjects. Washington, DC, Public Health Service, US Government Printing Office, 1963.

6. American Sleep Disorders Association. EEG arousals: scoring rules and examples. A preliminary report from the Sleep Disorders Atlas Task Force of the American Sleep Disorders Association. Sleep 1992; 15: 174-184.

7. Bland JM, Altman D. Statistical methods for assessing agreement between two methods of clinical measurement. Lancet 1986; 1: 307-310.

8. Wittig RM, Romaker A, Zorick FJ, Roehrs TA, Conway WA, Roth T. Night-to-night consistency of apneas during sleep. Am Rev Respir Dis 1984; 129: 244-246.

9. Condos R, Norman R, Krishnasamy I, Peduzzi N, Goldring $\mathrm{R}$, Rapoport D. Flow limitation as a noninvasive assessment of residual upper airway resistance during continuous positive airway pressure therapy of obstructive sleep apnea. Am J Respir Crit Care Med 1994: 150: 474480.

10. Shaheen MZ, Atkin M, Stone P, Woodcock A. Continuous phase-angle (PA) monitoring for the detection of sleep apnea syndrome (OSAS). Am Rev Respir Dis 1993; 147: A 809 (Abstract).

11. Launois SH, Cuartas JD, Garma L, Marchand F, Whitelaw WA, Derenne JP. Validation of a new screening device for obstructive sleep apnea. Am Rev Respir Dis 1993; 147: A 810 (Abstract).

12. Gyulay S, Gould D, Sawyer B, Pond D, Mant A, Saunders N. Evaluation of a microprocessor-based portable home monitoring system to measure breathing during sleep. Sleep 1987; 10: 130-142.

13. Walker LE, Walker JM, Farney RJ, Kramer J. A comparison of polysomnography with a portable home monitoring system in the detection of sleep apnea. Am Rev Respir Dis 1986; 133: A54 (Abstract).

14. Redline S, Tosteson T, Boucher MA, Millman R. Measurement of sleep-related breathing disturbances in epidemiologic studies: assessment of the validity and reproducibility of a portable monitoring device. Chest 1991; 100: 12811286.

15. Emsellem HA, Corson WA, Rappaport BA, Hackett S, Smith LG, Hansfeld JN. Verification of sleep apnea using a portable sleep apnea screening device. South Med J 1990; 83: 748-752. 
Appendix 1. - AHI values, sensitivity (Sens), specificity (Sp) and condordance (Kappa) between Full PSG and visual and different automatic NTRRV profiles using three different Full PSG AHI cut-off points: $>10,>20$ and $>30$ events.h-1. (For apnoea definition a fall in $\mathrm{Sa}_{\mathrm{O}} \mathrm{O}_{2}$ is compulsory).

\begin{tabular}{|c|c|c|c|c|c|c|c|c|c|c|c|c|}
\hline & PSG & Visual & FA80504 & FA80502 & FA80354 & FA80352 & F80504 & F80502 & F80354 & F80352 & A $4 \%$ & $\mathrm{~A} 2 \%$ \\
\hline \multicolumn{13}{|c|}{ a) Sensitivity, specificity and concordance of visual and some automatic NTRRV profiles compared to full PSG } \\
\hline AHI* & $35 \pm 4.3$ & $30 \pm 3.6$ & $19 \pm 3.4$ & $26 \pm 3.6$ & $20 \pm 3.4$ & $29 \pm 3.5$ & $15 \pm 3.2$ & $20 \pm 3.5$ & $19 \pm 3.4$ & $25 \pm 3.7$ & $17 \pm 3.3$ & $23 \pm 3.3$ \\
\hline Cut-off & Sens & 78 & 64 & 75 & 64 & 79 & 54 & 64 & 64 & 75 & 64 & 71 \\
\hline \multirow[t]{2}{*}{$>10$} & $\mathrm{Sp}$ & 57 & 86 & 71 & 86 & 71 & 100 & 100 & 86 & 86 & 86 & 57 \\
\hline & Kappa & 0.30 & 0.33 & 0.36 & 0.33 & 0.41 & 0.31 & 0.42 & 0.34 & 0.46 & 0.34 & 0.22 \\
\hline Cut-off & Sens & 94 & 72 & 83 & 72 & 83 & 56 & 78 & 67 & 83 & 56 & 78 \\
\hline \multirow{2}{*}{$>20$} & $\mathrm{Sp}$ & 82 & 88 & 76 & 88 & 71 & 100 & 88 & 94 & 76 & 88 & 76 \\
\hline & Kappa & 0.77 & 0.60 & 0.60 & 0.60 & 0.54 & 0.55 & 0.66 & 0.60 & 0.60 & 0.43 & 0.54 \\
\hline Cut-off & Sens & 94 & 53 & 76 & 58 & 82 & 41 & 53 & 47 & 76 & 41 & 47 \\
\hline \multirow{2}{*}{$>30$} & $\mathrm{Sp}$ & 94 & 100 & 83 & 100 & 83 & 100 & 100 & 100 & 89 & 100 & 94 \\
\hline & Kappa & 0.88 & 0.53 & 0.60 & 0.60 & 0.66 & 0.42 & 0.54 & 0.48 & 0.65 & 0.42 & 0.42 \\
\hline
\end{tabular}

b) Sensitivity, specificity and concordance of some automatic NTRRV profiles compared to visual scoring of NTRRV

\begin{tabular}{|c|c|c|c|c|c|c|c|c|c|c|c|}
\hline \multirow{3}{*}{$\begin{array}{l}\text { Cut-off } \\
>10\end{array}$} & Sens & 76 & 88 & 76 & 92 & 60 & 72 & 76 & 88 & 76 & 88 \\
\hline & $\mathrm{Sp}$ & 100 & 90 & 100 & 90 & 100 & 100 & 100 & 100 & 100 & 90 \\
\hline & Kappa & 0.64 & 0.73 & 0.64 & 0.80 & 0.46 & 0.60 & 0.64 & 0.81 & 0.64 & 0.73 \\
\hline \multirow{3}{*}{$\begin{array}{l}\text { Cut-off } \\
>20\end{array}$} & Sens & 75 & 90 & 75 & 90 & 50 & 80 & 65 & 90 & 60 & 85 \\
\hline & $\mathrm{Sp}$ & 100 & 93 & 100 & 86 & 100 & 100 & 100 & 93 & 100 & 93 \\
\hline & Карра & 0.72 & 0.83 & 0.72 & 0.77 & 0.46 & 0.77 & 0.61 & 0.83 & 0.56 & 0.77 \\
\hline \multirow{3}{*}{$\begin{array}{l}\text { Cut-off } \\
>30\end{array}$} & Sens & 53 & 82 & 59 & 88 & 41 & 53 & 47 & 82 & 41 & 53 \\
\hline & & 100 & 89 & 100 & 89 & 100 & 100 & 100 & 94 & 100 & 100 \\
\hline & Карра & 0.54 & 0.71 & 0.59 & 0.77 & 0.42 & 0.54 & 0.48 & 0.77 & 0.42 & 0.54 \\
\hline
\end{tabular}

*: mean \pm SEM. AHI: apnoea-hypopnoea index; PSG: polysomnography; NTRRV: nighttime recording of respiratory variables; $\mathrm{Sa}_{\mathrm{a}, \mathrm{O}_{2}}$ : arterial oxygen saturation.

Appendix 2. - AHI values, sensitivity (Sens), specificity (Sp) and condordance (Kappa) between Full PSG and visual and different automatic NTRRV profiles using three different Full PSG AHI cut-off points: $>10,>20$ and $>30$ events. $\mathrm{h}^{-1}$. (For apnoea definition a fall in $\mathrm{Sa}_{\mathrm{a}} \mathrm{O}_{2}$ is not compulsory).

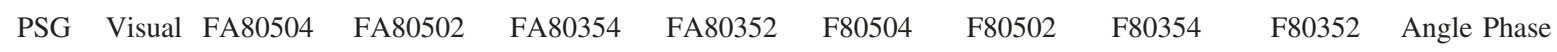

a) Sensitivity, specificity and concordance of visual and some automatic NTRRV profiles compared to full PSG

\begin{tabular}{llllllllllll} 
AHI* & $35 \pm 4.4$ & $30 \pm 3.6$ & $25 \pm 3.5$ & $30 \pm 3.5$ & $26 \pm 3.5$ & $32 \pm 3.5$ & $21 \pm 3.4$ & $24 \pm 3.6$ & $24 \pm 3.5$ & $28 \pm 3.7$ & $24 \pm 3.0$ \\
Cut-off & Sens & 78 & 71 & 82 & 71 & 86 & 64 & 68 & 71 & 82 & 86 \\
$>10$ & Sp & 57 & 85 & 43 & 71 & 28 & 87 & 71 & 71 & 57 & 42 \\
& Kappa & 0.30 & 0.41 & 0.23 & 0.32 & 0.15 & 0.42 & 0.28 & 0.32 & 0.35 & 0.28 \\
\multicolumn{1}{c}{ Cut-off } & Sens & 94 & 83 & 89 & 83 & 89 & 78 & 78 & 78 & 89 & 77 \\
$>20$ & Sp & 82 & 82 & 76 & 82 & 70 & 94 & 88 & 82 & 76 & 76 \\
& Kappa & 0.77 & 0.65 & 0.65 & 0.65 & 0.60 & 0.71 & 0.66 & 0.60 & 0.65 & 0.54 \\
Cut-off & Sens & 94 & 76 & 88 & 82 & 88 & 53 & 71 & 76 & 82 & 53 \\
$>30$ & Sp & 94 & 94 & 83 & 94 & 83 & 94 & 94 & 94 & 89 & 100 \\
& Kappa & 0.88 & 0.71 & 0.71 & 0.77 & 0.71 & 0.48 & 0.65 & 0.71 & 0.71 & 0.53
\end{tabular}

b) Sensitivity, specificity and concordance of some automatic NTRRV profiles compared to visual scoring of NTRRV

\begin{tabular}{lllllllllll} 
Cut-off & Sens & 84 & 96 & 84 & 100 & 72 & 80 & 84 & 92 & 96 \\
$>10$ & Sp & 100 & 70 & 90 & 60 & 100 & 90 & 90 & 70 & 60 \\
& Kappa & 0.75 & 0.70 & 0.68 & 0.68 & 0.60 & 0.72 & 0.68 & 0.64 & 0.61 \\
& & & & & & & & & & \\
Cut-off & Sens & 90 & 95 & 90 & 95 & 75 & 80 & 85 & 95 & 80 \\
$>20$ & Sp & 100 & 93 & 100 & 87 & 100 & 100 & 100 & 93 & 87 \\
& Kappa & 0.88 & 0.88 & 0.88 & 0.82 & 0.72 & 0.77 & 0.83 & 0.88 & 0.65 \\
& & & & & & & & & & \\
Cut-off & Sens & 76 & 94 & 82 & 94 & 53 & 70 & 76 & 89 & 53 \\
$>30$ & Sp & 94 & 89 & 94 & 89 & 94 & 94 & 94 & 93 & 100 \\
& Kappa & 0.71 & 0.83 & 0.77 & 0.83 & 0.58 & 0.65 & 0.71 & 0.83 & 0.54 \\
\hline
\end{tabular}

For abbreviations see legend to Appendix 1. 